\title{
Recovery hopes for the world's rarest primate
}

Hui Liu*, Heidi Ma, Susan M. Cheyne, Samuel T. Turvey

China was home to the world's second-highest diversity of gibbons in the 20th century, but these species have all suffered extensive population declines, and regional species losses continue $(1,2)$. The Hainan gibbon (Nomascus hainanus), formerly widespread across Hainan Island (3), is now the rarest primate and among the rarest mammals (4). It represents one of the oldest gibbon lineages (5) but has received limited conservation attention compared with many other species in China. Hunting and habitat loss have reduced the species to a single high-elevation population in Bawangling National Nature Reserve $(4,6)$. Restricted to $15 \mathrm{~km} 2$ of fragmented rainforest within this reserve, the Hainan gibbon has persisted with fewer than 30 individuals for several decades $(3,6,7)$. With China's plan to establish a national park on Hainan, the species has a renewed chance at recovery, but challenges remain.

Although the Hainan gibbon population received inconsistent financial support for protective measures in the 1980s and 1990s (6), conservation efforts since then have yielded promising signs. Two newly formed social groups were discovered in 2015 and 2019, and based on these positive trends, the total population size now likely exceeds 30 individuals (8). However, the species has extremely low genetic diversity (9), and forest degradation and conversion present barriers to the range expansion necessary for recovery (7). Increased enforcement has eliminated hunting as a threat $(6,7)$, but the tiny population is inherently vulnerable to stochastic events such as emerging zoonotic disease outbreaks and extreme climatic events. In 2015, the National Park system was established as China's new protected area framework (10). Hainan Tropical Rainforest National Park will be established in 2020 (11) and will cover almost one-seventh of Hainan's land area. The Hainan gibbon, as Hainan's endemic primate (2), has been designated the national park's flagship species (12). Raising the species' profile is an important step, but crucial data gaps remain, and national park management must be evidence-based and guided by new research. In addition to increasing funding, it is essential to improve monitoring with innovative technologies, to understand habitat structure and resource distribution, and to implement science-led forest restoration. In situ conservation remains the priority, but feasibility of intensive recovery strategies under potential emergency scenarios must be appraised (7). Assessment of future climate change impacts is also urgently needed. Effective Hainan gibbon conservation and long-term protection of China's tropical biodiversity requires robust scientific understanding, including insights from the recovery of other highly threatened species.

*Corresponding author. Email: liuhui@hainanu.edu.cn

\section{References:}

1. P. Fan, Biol. Conserv. 210, 29 (2017).

2. B. Li et al., Biodivers. Conserv. 27, 3301 (2018).

3. Z. Liu, S. Yu, X. Yuan, Chin. Wildl. 6, 1 (1984).

4. T. Geissmann, W. Bleisch, Nomascus hainanus (The IUCN Red List of Threatened Species, 2008).

5. V. N. Thinh et al., BMC Evol. Biol. 10, 74 (2010). 
6. B. P. L. Chan, J. R. Fellowes, T. Geissmann, J. Zhang, "Hainan gibbon status survey and conservation action plan" (Kadoorie Farm \& Botanic Garden, 2005).

7. S. T. Turvey et al., "International conservation planning workshop for the Hainan gibbon: Final report" (Zoological Society of London/IUCN SSC Conservation Breeding Specialist Group, 2015).

8. J. V. Bryant et al., Int. J. Primatol. 37, 534 (2016).

9. J. V. Bryant et al., Mol. Ecol. 25, 3540 (2016).

10. J. Li et al., Science 351, 1160 (2016).

11. "China makes headway in protecting tropical rainforests," Xinhua (2020).

12. "Speed up the construction of Hainan Rainforest National Park in 2020," ChinaNews (2020). http://www.hi.chinanews.com/hnnew/2020-01-23/513006.html [in Chinese].

Competing Interests

S.M.C. is vice-chair of the International Union for Conservation of Nature/Species Survival Commission Primate Specialist Group's Section on Small Apes. 